\title{
Assessment of Closed Head Injury in Trauma-related Spinal Cord Injury
}

\author{
Gary Davidoff, M.D., ${ }^{1}$ Elliot Roth, M.D., ${ }^{1}$ Jeri Morris, Ph.D., ${ }^{2}$ Joseph \\ Bleiberg, Ph.D. ${ }^{2}$ and Paul R. Meyer, Jr., M.D. ${ }^{3}$ \\ ${ }^{1}$ Departments of Rehabilitation Medicine, ${ }^{2}$ Psychiatry and ${ }^{3}$ Orthopedic Surgery, \\ Northwestern University Medical School and The Rehabilitation Institute of \\ Chicago, Chicago, Illinois
}

\section{Summary}

The complete medical records of 122 patients who sustained traumatic spinal cord injuries were reviewed to determine the frequency and results of emergency room assessments for loss of consciousness (LOC) and post-traumatic amnesia (PTA). Eighty-eight percent of the patients were assessed for LOC and $19 \%$ were assessed for PTA. Fifty patients ( $41 \%$ of the total population) admitted to LOC, PTA or both. Fourteen of these 50 patients underwent subsequent radiographic examinations of the skull, all of which were negative. Because of the association of intracranial complications and long-term cognitive sequelae with even brief LOC or PTA, early recognition of craniocerebral trauma is an important component of the acute management of spinal cord injured patients.

Key words: Traumatic spinal cord injury; Closed head injury; Traumatic amnesia.

\section{Introduction}

Patients who sustain a mild closed head injury are at risk from the development of intracranial complications and the effects of direct cerebral trauma. The intracranial sequelae, includiing haematoma and infection, are potentially reversible with prompt medical and surgical intervention when recognized early. Likewise, direct cerebral injury, as evidenced by even brief loss of consciousness or anterograde (post-traumatic) amnesia, may be associated with significant disturbances in cognitive functioning (Russell, 1932; Denny-Brown, 1945; Russell and Smith, 1961; Steadman and Graham, 1970; Gronwall and Wrightson, 1974; Rimel et al., 1981) and emotional (Lishman, 1973; Dikman and Reitan, 1977; Levin, 1978; Fordyce et al., 1983). These disturbances may be amenable to therapy following early identification of patients at risk with cerebral dysfunc-

Read at the Annual Scientific Meeting of the International Medical Society of Paraplegia, Denver, Colorado. June, 1984; and at the 14th UAEM Annual Meeting, Louisville, Kentucky. May, 1984.

Address for correspondence: Jeri Morris, Ph.D., Rehabilitation Institute of Chicago, Psychology Department, Room 903, 345 East Superior, Chicago, Illinois 60611. 
tion. This would allow for timely referral for further neuropsychological evaluation which can facilitate appropriate modification in rehabilitation programmes.

Previous studies have demonstrated that many traumatic spinal cord injured patients may have sustained a concomitant head injury (Guttmann, 1963; Meinecke, 1968; Harris, 1968; Silver et al., 1980; Young et al., 1982; Schueneman and Morris, 1982; Dubo and Delaney, 1984; Wagner et al., 1984; Wilmot et al., 1984). Early recognition of craniocerebral trauma in the spinal cord injured patient is important in order to plan appropriate evaluation and treatment. The present study was undertaken to determine the frequency of assessment and prevalence of closed head injury in patients presenting to an emergency department with traumatic spinal cord injury. This study was stimulated by an emerging awareness of the implications of concomitant head and spinal cord injuries by the acute spinal cord injury care team.

\section{Method}

A review was conducted of the complete medical records of 122 patients presenting to the Northwestern Memorial Hospital Emergency Room (NMHER) between August 1981 and October 1983 with traumatic spinal cord injuries. All patients were admitted to the NMH-ER within 7 days of injury; $92 \%$ were admitted within 48 hours of injury. All patients were transferred from the NMH-ER to the Northwestern Memorial Hospital Spinal Cord Injury Unit for acute care and then to the Rehabilitation Institute of Chicago for initial rehabilitation. During this period, the NMH-ER admitted $71 \%$ of all patients with acute spinal cord injuries that occurred in Chicago, Illinois, and $39 \%$ of all patients with spinal cord injuries that occurred in the state of Illinois (Mid-west Regional Spinal Cord Injury Care System, 1980). All patients were 17 years of age or older at the time of admission to the NMH-ER.

A review of the emergency room (ER) assessments was conducted. Data were obtained regarding aetiology of injury and level of injury, defined as the last complete level of intact neurologic function or the most inferior intact vertebral level on myelography (whichever was more cephalad). The data base included whether inquiries for loss of consciousness (LOC) and post-traumatic amnesia (PTA) were documented, and if so, the results of these inquiries. The state of post-traumatic amnesia is characterized by an inability to store new memories. If a positive history of LOC and/or PTA was noted during the ER assessment, a review of the radiographic reports was conducted to determine whether further investigations for head injury, including plain radiography or computed tomography of the skull, was performed. In the ER, the spinal cord injured patients were evaluated by physicians from the departments of neurosurgery, orthopaedics, critical care, and trauma. Assessment of LOC or PTA was considered to have been performed if any of these physicians documented such an assessment in the medical record.

Data were analysed using the chi-square technique.

\section{Results}

Classification data of all spinal cord injured patients included in the study are 
Table 1 Description of Study Population: 122 acute trauma-related spinal cord injured patients

\begin{tabular}{|c|c|c|c|c|c|c|}
\hline \multirow{2}{*}{$\begin{array}{c}\text { Age } \\
\text { (years) }\end{array}$} & \multicolumn{2}{|c|}{ Sex } & \multicolumn{2}{|c|}{ Level of Injury } & & \\
\hline & Male & Fethale & $\mathrm{C} 1-\mathrm{T} 6$ & T7-S2 & \multicolumn{2}{|l|}{ Aetiology of injury } \\
\hline $17-75$ & $\begin{array}{c}106 \\
(87 \%)\end{array}$ & $\begin{array}{c}16 \\
(13 \%)\end{array}$ & $\begin{array}{c}95 \\
(78 \%)\end{array}$ & $\begin{array}{c}27 \\
(22 \%)\end{array}$ & $\begin{array}{l}\text { Motor Vehicle Accidents } \\
\text { Falls } \\
\text { Sports and Diving } \\
\text { Gunshot Wounds } \\
\text { Assaults }\end{array}$ & $\begin{array}{r}46(38 \%) \\
34(28 \%) \\
21(17 \%) \\
20(16 \%) \\
1(1 \%)\end{array}$ \\
\hline
\end{tabular}

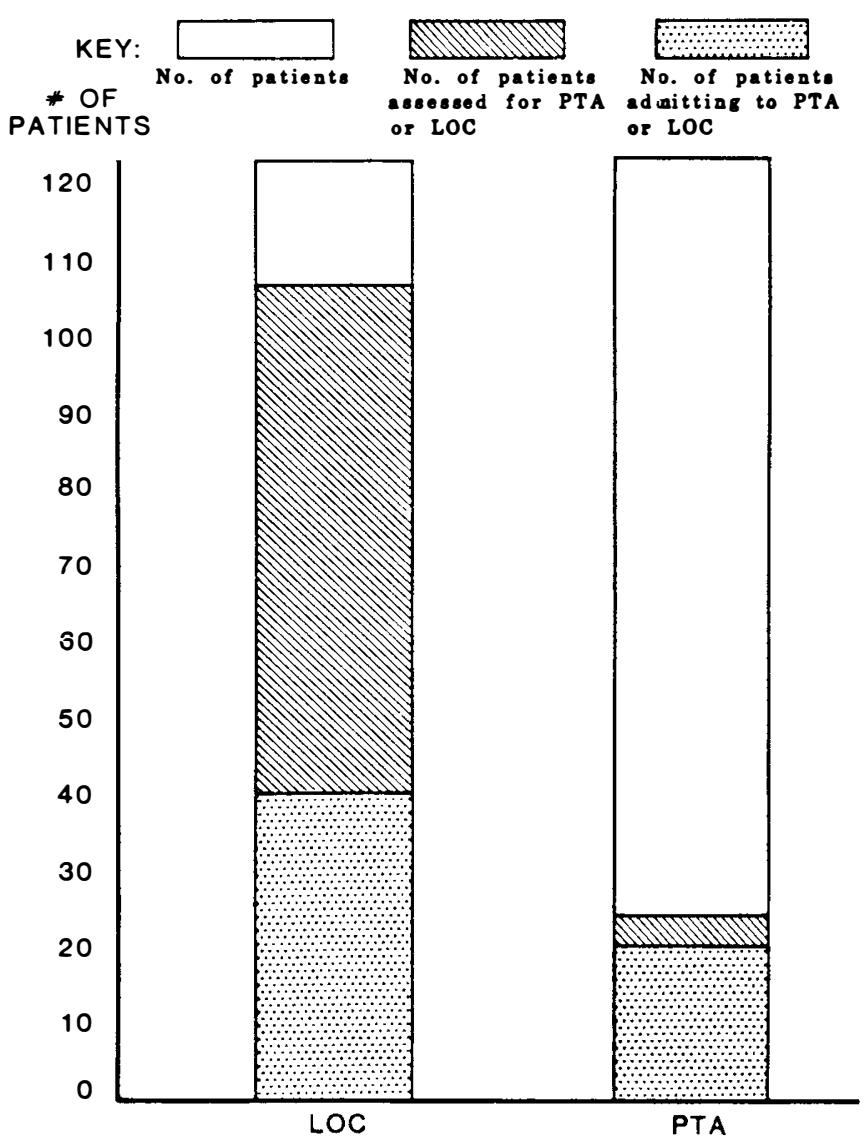

Figure 1. ER Assessment of LOC and PTA for Total Population.

presented in Table 1. Seventy-eight percent of the patients sustained injuries between the $\mathrm{C} 1$ and $\mathrm{T} 6$ levels and $22 \%$ sustained injuries between the T7 and S2 levels. Spinal cord injuries were caused, in descending order of frequency, by motor vehicle accidents, sports and diving injuries, falls, gunshot wounds, and assaults.

Frequency and results of closed head injury assessments are presented in Figures 1-3. Eighty-eight percent of all patients were assessed for LOC and 


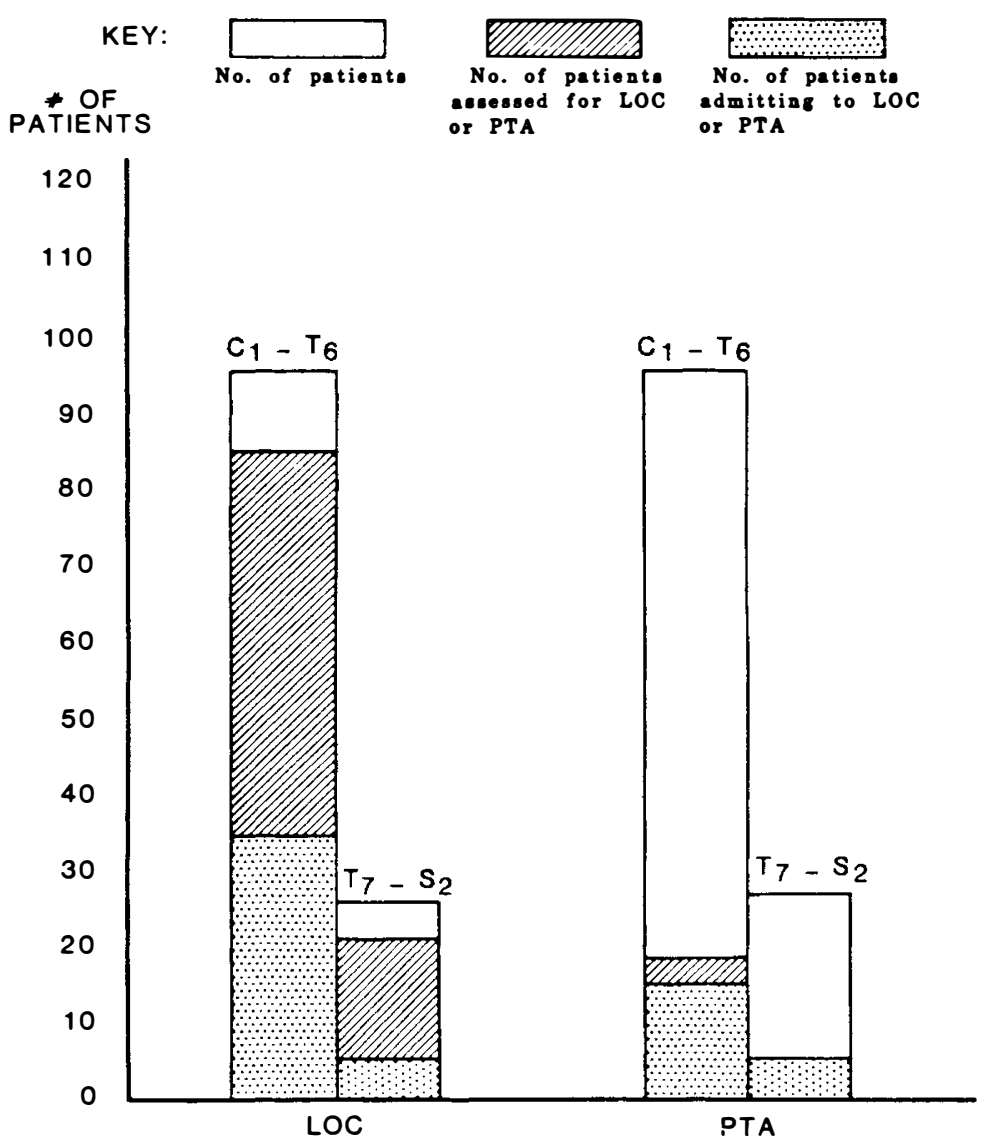

Figure 2. ER Assessment of LOC and PTA by Level of Injury.

$19 \%$ were assessed for PTA. Level of injury did not influence assessment, but aetiology did. LOC was assessed in $55 \%$ of gunshot wound victims and in $94 \%$ of all other patients $(p<.001)$. PTA was assessed too infrequently to provide a meaningful comparison of its assessment between aetiologic types.

Thirty-eight percent of those patients who were assessed admitted to LOC and $87 \%$ of those assessed admitted to PTA. Level of injury did not influence the presence or absence of these symptoms, but aetiology did. None of the gunshot wound victims for whom assessments were performed lost consciousness, but $42 \%$ of all non-gunshot wound patients who were assessed admitted to LOC $(\mathrm{p}<.02)$.

Of the 122 patients evaluated in the ER, 30 admitted to LOC alone, 10 admitted to PTA alone, and an additional 10 admitted to having sustained both LOC and PTA. Fourteen of these 50 patients underwent subsequent radiological examinations, including plain radiography and/or computed tomography of the skull (Figure 4). None of these radiographic studies demonstrated a skull fracture or midline shift. 


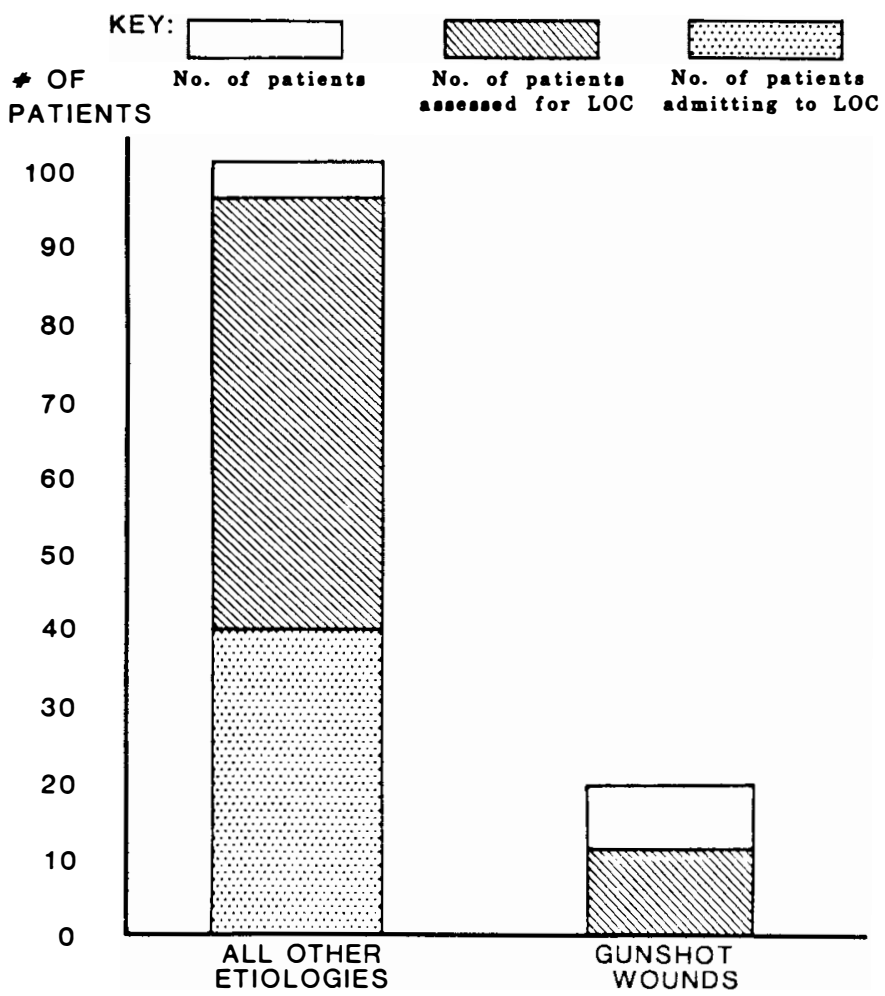

Figure 3. ER Assessment of LOC by Etiology of Injury.

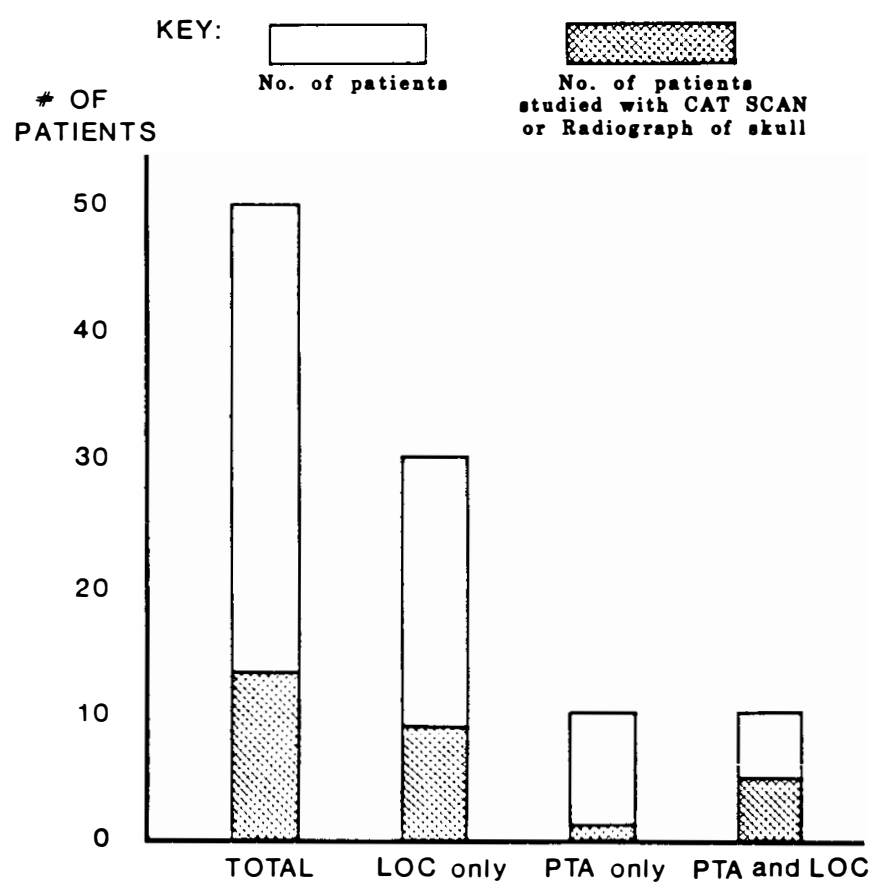

Figure 4. Radiological study of Head Injury in Acute Traumatic SCI. 


\section{Discussion}

A thorough emergency department evaluation of patients who sustain central nervous system injuries directs the acute management of these injuries and modifies long-term rehabilitation approaches. Findings of the present study support the results of several previous reports (Guttmann, 1963; Meinecke, 1968; Silver et al., 1980; Young et al., 1982; Schueneman and Morris, 1982; Dubo and Delaney, 1984; Wagner et al., 1984; Wilmot et al., 1984) that patients who present to emergency rooms with trauma-related spinal cord injuries frequently sustain a concurrent head injury at the time of trauma.

In the present investigation, loss of consciousness (LOC) was assessed far more consistently than post-traumatic amnesia (PTA). Level of spinal cord injury did not influence assessment, but aetiology did. LOC was assessed half as often in gunshot wound victims as compared with all other etiologies combined. PTA was infrequently assessed despite its sensitivity in detection and estimation of severity of head injury (Russell, 1932; Russell and Smith, 1961; Smith, 1961; VonWowern, 1966; Steadman and Graham, 1970).

Forty-one percent of the 122 patients evaluated in the emergency room provided histories consistent with closed head injury, defined as LOC, PTA or both, sustained at the time of trauma. This is probably a conservative estimate because PTA assessment was infrequently performed; patients who denied LOC may have sustained a PTA period that was not assessed, as suggested by the finding that $50 \%$ of the patients who admitted to PTA denied LOC.

Early identification of patients with presumptive evidence of even a mild closed head injury affects the emergency room management of these patients. Altered consciousness is often considered a criterion for radiographic skull examinations (Bell and Loop, 1971; FDA Drug Bull., 1978). Several authors have reported a 5-13\% incidence of radiographic abnormalities in patients with histories consistent with mild head injuries and no neurological deficits (French and Dublin, 1977; Strang et al., 1978; De Lacey et al., 1980; Jennett, 1980; Rimel et al., 1981). Skull fracture is a significant risk factor associated with complications following head injuries in adults. The vast majority of patients with intracranial haematomas present with linear skull fractures (Galbraith, 1973; Galbraith and Smith, 1976; Jennett, 1980), and depressed skull fractures carry an added risk of complications (Miller and Jennett, 1968; Braakman, 1972; Jennett and Miller, 1972). In the present study, $28 \%$ of the 50 patients with presumptive evidence of a closed head injury underwent radiological evaluation of skull fracture, none of which had positive findings.

Diagnosis of a mild closed head injury concurrently in patients presenting with a traumatic spinal cord injury influences their physiatric care. A LOC of 20 minutes or a PTA of 24 hours has been associated with deficits in attention, concentration, memory, higher cognitive functions and prolonged time off work (Russell, 1932; Denny-Brown, 1945; Russell and Smith, 1961; Steadman and Graham, 1970; Gronwall and Wrightson, 1974; Rimel et al., 1981). Some of these sequelae may impede the learning of new skills and information during the acute care and rehabilitation hospitalization. Determination of patients who sustain LOC and/or PTA would permit early identification of patients at risk for these sequelae. This information would allow for in-depth neuropsychological 
testing and would facilitate appropriate modifications of psychiatric treatment strategies.

The multiplicity of problems with which the acute spinal cord injury patient presents to the emergency room necessitates the establishment of priorities in evaluation and care. The apparently "less critical" closed head injury may be overlooked during this period. Results of the present study confirm those of other investigators that a mild closed head injury may frequently be associated with a traumatic spinal cord injury. Further, many patients with head injuries remain unrecognized. Failure to identify the presence of a mild closed head injury in spinal cord injured patients may adversely affect their immediate and long-term outcome by enhancing the risk of missing intracranial complications and cognitive impairments.

\section{Addendum}

The message of this paper is the importance of a comprehensive initial assessment of the acute spinal cord injury patient for the presence of craniocerebral trauma. Because there is no clear association between level of spinal injury and evidence of craniocerebral trauma, paraplegic patients warrent the same rigor of assessment as quadriplegics. Radiographic assessment may identify individuals at risk for intracranial complications who may benefit from more intensive monitoring of craniocerebral function.

\section{Résumé}

On a revu la fiche médicale complète de 122 malades qui avaient subi des blessures traumatiques de la moelle épinière pour déterminer la fréquence et les résultats des évaluations en salle d'urgence de perte de connaissance (LOC) et d'amnésie post-traumatique (PTA). On a évalué quatre-vingt-huit pour cent des malades sous la LOC et $19 \%$ sous la PTA. Cinquante malades $(41 \%$ de la population totale) ont avoué LOC, PTA ou toutes deux. Quatorze de ces 50 malades ont subi un examen radiographique ultérieur du crâne, dont tous se sont montrés négatifs. A cause de l'association des complications intracraniales et des séquelles de longue durée pour la connaissance avec LOC ou PTA, même brève, reconnaître le plus tôt possible le traumatisme cérébrocranial est un élément important du traitement en cas aigu des malades qui souffrent de blessures de la moelle épinière.

\section{Zusammenfassung}

Man hat die vollständigen medizinischen Archiven von 122 Patienten, die an traumatischen Rückenmarkverletzungen gelitten hatten, durchgeschaut, um die Häufigkeit und die Ergebnisse von Notraumbewertungen für Bewusstseinsverlust (LOC) und posttraumatische Amnesie (PTA) zu bestimmen. Achtundachtzig Prozent der Patienten sind für LOC und $19 \%$ für PTA bewertet worden. Fünfzig Patienten ( $41 \%$ der Gesamtpatientenbevölkerung) haben LOC, PTA oder beide zugegeben. Vierzehn von diesen 50 Patienten haben sich späteren Röntgenuntersuchungen des Schädels unterzogen, wovon alle negativ waren. Wegen der Verbindung von intrakranialen Komplikationen und dauerhaften für das Erkennungsvermögen schädlichen Folgeerscheinungen mit LOC bzw. PTA, auch wenn diese kurzfristig sind, ist eine frühzeitige Erkennung von kraniozerebralem 'Trauma ein wichtiges Element der akuten Behandlung von rückenmarkverletzten Patienten.

\section{References}

BELL RS, LOOP JW 1971 The utility and futility of radiographic skull examinations for trauma. New England Journal of Medicine 284:236-239.

BRAakman R 1972 Depressed skull fracture: Data, treatment, and follow-up in 225 consecutive cases. Journal of Neurology, Neurosurgery and Psychiatry 35:395-400.

Delacey G, Guilding A, Wignall B, et al. 1980 Mild head injuries: A source of excessive 
radiography? (Analysis of a series and reivew of the literature). Clinical Radiology 31:457-462.

DENNY-BROWN D 1945 Disability arising from closed head injury. Journal of American Medical Association 127:429-436.

Dikman S, Reitan RM 1977 Emotional sequelae of head injury. Annals of Neurology 2:492-494.

Dubo H, Delaney G 1984101 spinal cord injuries due to motor vehicle accidents. Proceedings of the American Spinal Injury Association. pp. 35-38.

FDA Drug Bulletin. 1978 8:30-31.

Fordyce DJ, Roueche JR, Prigatano GP 1983 Enhanced emotional reactions in chronic head trauma patients. Journal of Neurology, Neurosurgery and Psychiatry 46:620-624.

FRENCH BN, DUBLIN AB 1977 The value of computerized tomography in the management of 1000 consecutive head injuries. Surgical Neurology 7: 171-183.

GaLBRAITH SL 1973 Age distribution of extradural haemorrhage without skull fracture. Lancet 1:1217-1218.

GalbRAITH SL, SMIth J 1976 Acute traumatic intracranial haematoma without skull fracture. Lancet 1:501-503.

Gronwall D, WRIGHTSON P 1974 Delayed recovery of intellectual function after minor head injury. Lancet 2:605-609.

GuttmanN L 1963 Proceedings of Symposium on spinal injuries, p. 81, Roy Coll Surg: Edinburgh.

HARRIS P 1968 Associated injuries in traumatic paraplegia and tetraplegia. Paraplegia 5: 215-220.

JENNETT B 1980 Skull x-rays after recent head injury. Clinical Radiology 31:463-469.

JENNETT B, MilleR JD 1972 Infection after depressed fracture of skull: Implications for management of non-missile injuries. Journal of Neurosurgery 36:333-340.

Levin HS, Grossman RG 1978 Behavioural sequelae of closed head injury: A quantitative study. Archives of Neurology 35:720-727.

Lishman WA 1973 The psychiatric sequelae of head injury: A review. Psychological Medicine 3:304-318.

MEINECKE FW 1968 Frequency and distribution of associated fractures in traumatic paraplegia and tetraplegia. Paraplegia 5:196-211.

Midwest Regional Spinal Cord Injury Center 1980 Report No. 9, Northwestern UniversityMcGraw Medical Centre, Chicago.

Miller JD, Jennett B 1968 Complications of depressed skull fracture. Lancet 2:991-995.

RIMEL RW, GIORDANI B, BARTH JT, et al. 1981 Disability caused by minor head injury. Neurosurgery 9:221-228.

RUSSELL WR 1932 Cerebral involvement in head injury. Brain 55:549-603.

RuSSELl WR, SMITH A 1961 Post-traumatic amnesia in closed head injury. Archives of Neurology 5:4-17.

SCHUENEMAN A, MORRIS J 1982 Neuropsychological deficits associated with SCI. SCI Digest 4:35-64.

SILVER JR, MORRIS WR, OTFINOWSKI JS 1980 Associated injuries in patients with spinal injury. Injury 12:219-224.

SMITH A 1961 Duration of impaired consciousness as an index of severity in closed head injury: A review. Dis Nerv Syst 22:69-74.

Steadman JH, Graham JG 1970 Head injuries: An analysis and follow-up study. Proceedings of the Royal Society of Medicine 63:23-28.

Strang I, MacMillan R, JenNett B 1978 Head injuries in accident and emergency departments at Scottish hospitals. Injury 10:154-159.

VONWOWERN FF 1966 Post-traumatic amnesia and confusion as an index of severity in head injury. Acta Neurologica Scandinavica 42:373-378.

WAGNer KA, Kopaniky DR, Esposito L 1984 Combined head and spinal cord injury: Potential for errors in diagnosis and treatment. Proceedings of the American Spiral Injury Association, pp. 96-104.

Wilmot CB, Cope DN, Hall KM, et al. 1984 Incidence of occult head injury in those with a primary diagnosis of spinal cord injury. Proceedings of the American Spinal Injury Association, pp. 105-108.

YOUNG JS, BURNs PE, Bowen AM, et al. 1982 Spinal cord injury statistics: Experience of the regional spinal injury sytems, p. 34, Good Samaritan Medical Centre, Phoenix. 